\title{
Implikasi Erupsi Gunung Agung Terhadap Sosial Ekonomi Pelaku Usaha Pariwisata Di Kawasan Pantai Batu Bolong, Canggu
}

Dewi Sasmita a, 1 , Saptono Nugroho a, 2

1dewisasmita8@gmail.com,2 saptono_nugroho@unud.ac.id

a Program Studi Sarjana Destinasi Pariwisata, Fakultas Pariwisata Universitas Udayana, Jl. Dr. R. Goris, Denpasar, Bali 80232 Indonesia

\begin{abstract}
The eruption of Mount Agung has an immense impact on Bali, especially in the economic sector of the tourism business. The locations which are far from Gunung Agung have been affected especially in the Southern part of Bali which has a higher growth of tourism compared to the rest. This is interesting to study especially in the tourism related business namely the Batu Bolong Beach area. The purpose of this study is to determine the posteruption implications of Mount Agung that have hit Bali in terms of the socio-economic aspects of tourism stakeholders and the existing business conditions in the Batu Bolong Beach area. As well as knowing the crisis management system in the tourism in Batu related business at Batu Bolong Beach and seeking at the situation and condition those who work for tourism related businesses at the Batu Bolong Beach area.The research methodology used in this study is qualitative research. Where qualitative uses in-depth interview techniques, observations and qualitative documents as well as using the concept of socio-economic impacts of tourism to see the socio-economic impacts arising from the eruption of Mount Agung. The results shows the conditions of tourism businesses after the eruption, theses include: type of business, product range and price, tourist visits, post-eruption economic income. Another result is the socioeconomic condition of tourism stakeholder in the Batu Bolong Beach area.

Key word: Implication social economic tourism, Mount Agung Eruption, Tourism business
\end{abstract}

\section{Latar Belakang}

Erupsi Gunung Agung dewasa ini menjadi krisis baru di Bali. Terakhir Gunung Agung meletus pada bulan Februari tahun 1963. Erupsi yang terjadi kala itu cukup lama yakni hingga Januari 1964. Namun aktivitas Gununga Agung pada saat itu bersifat magmatis. Pada tanggal 18 September 2017 status Gunung Agung menjadi siaga, dimana aktifitas gempa tektonik semakin menguat berdasarkanpengamatan visual dan instrumental (Yoman dalam Bhaskara, 2017) . Gunung Agung erupsi kembali hingga setiap bulannya mengalami peingkatan status mulai dari siaga hingga awas. Penurunan aktivitas terjadi sekitar awal tahun 2018. Krisis bencana alam ini menyebabkan banyak dampak bagi segala bidang. Yang paling terasa mengalami dampak ialah pada bidang Pariwisata. Karena pariwisata telah menjadi elemen yang tidak dapat dipisahkan dengan Pulau Bali. Krisis bencana erupsi Gunung Agung menyebabkan penurunan kunjungan wisatawan. Hal ini karena banyaknya isu negatif yang berkembang di Pulau Bali. Penurunan kunjungan wisatawan ke Bali menyebabkan elemen pariwisata melemah terutama pada sosial ekonomi para pelaku usaha pariwisata. Penurunan jumlah kunjungan wisatawan mancanegara dapat dilihat pada tabel 1 berikut ini:
Tabel 1

Tingkat kunjungan wisatawan mancanegara ke Bali periode bulan September 2017 hingga bulan Januari 2018

\begin{tabular}{|c|c|c|c|c|c|}
\hline Bulan & September & Oktober & November & Desember & Januari \\
\hline Jumlah & 550.520 & 465.085 & 361.006 & 315.909 & 358.065 \\
& & & & & \\
\hline
\end{tabular}

Sumber: bali.bps.go.id

Dengan menurunnya kunjungan wisatawan, sektor pariwisata mengalami krisis yang paling terasa. Dampak penurunan saat erupsi Gunung Agung tersebut adalah dampak soial ekonomi, sosial budaya bahkan lingkungan dalam pariwisata Bali. Seperti sektor ekonomi lainnya, industri pariwisata sangat rentan terhadap bencana alam kerentanan fisik berupa infrastrukutr dan non takberwujud seperti citra dan repuasi (Bhaskara,2017). Seluruh stakeholders pariwisata seperti pengusaha, pemerintah, masyarakat dan wisatawan merasakan dampak tersebut. Stakeholders pariwisata yang sangat merasakan dampaknya selain masyarakat adalah pengusaha pariwisata. Terlebih usaha pariwisata yang mengandalkan kunjungan wisatawan sebagai pasarnya. Dan hal ini sangat mendesak untuk di teliti dalam dampak sosial ekonomi yang dialami pelaku usaha pariwisata pasca erupsi Gunung Agung agar dapat 
memanajemen krisis yang dialami oleh usaha pariwisata Canggu bahkan di seluruh Provinsi Bali. Sasaran dalam penelitian ini adalah pengusaha pariwisata dan karyawan dalam usaha pariwisata. Lokasi penelitian akan dilakukan di kawasan Pantai Batu Bolong.

Pantai Batu Bolong memang terbilang jauh dari lokasi Gunung Agung namun hal ini menarik untuk diteliti untuk mengetahui sejauh mana dampak dari erupsi Gunung Agung terhadap usaha pariwisata walaupun jarak yang jauh sekalipun dari Gunung Agung itu sendiri. ditambah dengan pembesaran isu negatif mengenai erupsi Gunung Agung terhadap Provinsi Bali.

\section{TINJAUAN PUSTAKA \\ Dampak Sosial Ekonomi Pariwisata}

Menurut Cohen dalam (Pitana, 2005) dampak sosial ekonomi pariwisata dalam delapan kelompok besar yaitu: (1) Dampak penerimaan devisa, (2) Dampak pada pendapatan masyarakat, (3) Dampak kesempatan kerja, (4) Dampak pada hargaharga, (5) Dampak distribusi manfaat/keuntungan, (6) Dampak kepemilikan dan kontrol, (7) Dampak pembangunan secara umum, dan (8) Dampak pada pendapatan pemerintah.

\section{Manajemen Krisis}

Krisis merupakan keadaan yang tidak stabil dimana perubahan yang cukup menentukan mengancam, baik perubahan yang diharapkan maupun yang tidak diharapkan akan memberikan hasil yang lebih baik (Fink,1986). Langkah yang perlu dilakukan dalam manajemen krisis:

1. Identifikasi krisis

Pekerjaan ini dilakukan persis seperti seorang

2. Analisis krisis

3. Isolasi krisis

4. Pilihan strategi

5. Program pengendalian

\section{Usaha Pariwisata}

Menurut Undang-undang no.10 tahun 2009 Bab I pasal 1 tentang kepariwisataan menjelaskan definisi usaha pariwisata adalah usaha yang menyediakan barang dan/atau jasa bagipemenuhan kebutuhan wisatawan dan penyelenggaraan pariwisata. Pada Undangundang no. 9 tahun 1990 Bab I pasal 1 menyebutkan definisi usaha pariwisata adalah kegiatan yang bertujuan menyelenggarakan jasa pariwisata atau menyediakan atau menguhasakan objek dan daya tarik wisata usaha sarana pariwisata, dan usaha terkait pada bidang tersebut.

\section{Pekerja Usaha Pariwisata}

Dalam Undang-undang nomor 13 tahun 2003 tentang ketenagakerjaan menjelaskan definisi ketenagakerjaan pada bab I pasal 1 adalah segala hal berhubungan dengan tenaga kerja pada sebelum, selama dan sesudah masa kerja.

\section{METODOLOGI PENELITIAN}

Metode yang digunakan dalam penelitian ini adalah metode kualitatif deskriptif dengan teknik penentuan informan yaitu teknik purposive sampling. Data dalam penelitian ini diperoleh dari sumber primer dan sekunder dengan teknik pengumpulan data yang dilakukan yaitu observasi, wawancara mendalam dan studi dokumentasi.

Analisis data mulai dilakukan saat penyusunan konseptual penelitian, pengumpulan data dilapangan dan setelahnya. Kemudian dilakukan reduksi data untuk memilah, menajamkan, mengarahkan, dan membuang data yang tidak diperlukan. Penyajian data dilakukan dalam bentuk teks naratif. Selanjutnya ditarik simpulan yang diverifikasi selama penelitian berlangsung.

\section{HASIL DAN PEMBAHASAN}

\subsection{Gambaran Umum}

Desa Canggu ini memiliki daya tarik wisata bahari dengan kegiatan yang dapat dilakukan adalah surfing di Pantai Batu Bolong. Ramainya wisatawan yang mengunjungi Pantai Batu Bolong dengan demikian tumbuh pula usaha pariwisata yang beraneka ragam seperti jasa akomodasi, food and baverage, hingga hiburan malam tersedia di Desa Canggu. Desa Canggu mendapatkan pendapatan dari sektor pariwisata terutama dari jasa akomodasi dan restoran. Dalam dokumen profil Desa Batubolong jumlah penyedia jasa akomodasi yakni sebanyak 453 unit, menyumbang devisa sebesar Rp. 49.200.000,-. Sedangkan penyumbang devisa dari sektor pariwisata lainnya yakni dari jasa food and baverage sebanyak 15 unit sebesar Rp. 98.000.000,-. 
Dengan demikian sektor pariwisata menyumbang tidak sedikit untuk pengembangan desa. Berdasarkan hal tersebut sangat mendesak untuk mengetahui bagaimana kondisi sosial ekonomi pada usaha pariwisata yang berada di kawasan Pantai Batu Bolong, mengingat usaha pariwisata pada kawasan ini turut menyumbang untuk pendapatan desa dan pengembangan Desa Canggu.

\subsection{Kondisi Usaha Pariwisata yang ada di Kawasan Pantai Batubolong, Canggu}

1. Jenis usaha

a. Bali Laksita Home Stay

Usaha bergerak pada bidang akomodasi dengan bangunan nuansa modern namun masih mengusung tradisional Bali. memiliki sembilan ruang kamar dengan fasilitas beragam.

\section{Gambar 1 Teras Bali Laksita Home stay}

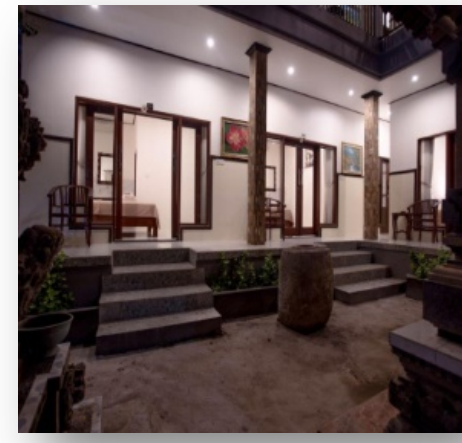

Sumber: hasil penelitian 2018

b. The Calmtree Bungalows

Usaha ini bergerak dalam bidang akomodasi yang mengusung tema tradisional Bali dan ramah lingkungan. Dapat dilihat pada gambar 2 mengenai deskripsi pintu masuk lingkungan The Calmtree Bungalows.

\section{Gambar 2 The Calmtree Bungalows}

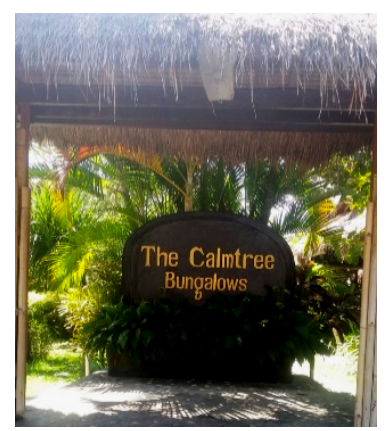

\section{Sumber: hasil penelitian 2018}

c. Old Man's

Bergerak dalam bidang penyedia jasa makanan dan minuman sejak tahun 2013 dengan luas berkisar 18 hektar. Konsep yang diterapkan adalah bajak laut yang rustic tanpa sentuhan nuansa modern.

\section{Gambar 3 Old Man's}

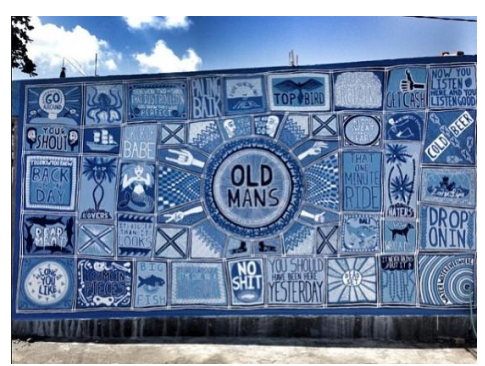

Sumber: hasil penelitian 2018

\section{Produk yang ditawarkan dan harga}

a. Bali laksita menawarkan jasa persewaan kamar sebanyak sembilan ruang dengan kisaran harga permalam sebesar Rp.400.000,- denngan fasilitas $A C$, wifi, water heater, sarapan sesuai permintaan tamu.

b. The Calmtree Bungalows menawarkan jasa persewaan kamar dengan 5 klasifikasi kamar double bed, twin, family room,dan private villa. Harga yang ditawarkan berkisar Rp. 700.000,hingga Rp. 1.500.00,- dengan fasilitas kipas angina, kolam renang wifi, dan sarapan pagi.

c. Old Man's menawarkan produk makanan dan minuman. Makanan barat sampai makanan Asia ditawarkan, minuman beralkohol dan minuman tidak beralkohol juga disediakan. Harga berksar Rp. 10.000,- hingga Rp. 1.750.000,-

\section{Kunjungan wisatawan pada usaha} pariwisata

Pada tingkat kunjungan wisatawan cukup beragam mulai dari yang menurun hingga stabil pasca erupsi terjadi. Usaha yang mengalami penururnan yakni Bali Laksita Homestay dan The Calmtree Bungalow mencapai $30 \%$ hungga 50\% yang diakibatkan oleh wisatawan yang akan berkunjung ke Bali mengalami delay saat erupsi terjadi, selain itu 
wisatawan membatalkan pesanannya. Untuk pendapatan yang didapat hanya dari perpanjangan waktu oleh wisatawan yang memang sudah menginap di Bungalow tersebut.

Usaha pariwisata lain yang mengalami penurunan adalah Bali Laksita Homestay yang mengalami penurunan mencapai $50 \%$ namun masih mendapat kunjungan dari wisatawan yang melakukan aktivitas surfing di Pantai Batubolong.

\section{Pendapatan Ekonomi Usaha Pariwisata Pasca Erupsi}

Pendapatan berkaitan dengan tingkat kunjungan wisatawan pada usaha pariwisata. Apabila kunjungan stabil maka pendapatan juga stabil begitu pula sebaliknya apabila terjadi penururnan kunjungan wisatawan maka terjadi penurunan pendapatan usaha pariwisata tersebut. dalam hal ini sebsui yang telah dijabarkan pada tingkat kunjungan yang mengalami penurunan adalah usaha The Calmtree Bungalow dan Bali Laksita Homestay. Penurunan pendapatan berkisar 50\%.

\subsection{Kondisi Sosial Ekonomi Pekerja pada Usaha Pariwisata di Kawasan Pantai Batubolong.}

\section{Kebijakan Usaha Pariwisata}

Tidak adanya kebijakan baru pada usaha pariwisata di kawasan Pantai Batubolong pasca erupsi terjadi. Bali Laksita Homestay yang mengalami penurunan berkisar 50\% tidak mempunyai kebijakan khusus karena pengelolaan homestay dikelola secara kekeluargaan tanpa ada penambahan karyawan. The Calmtree Bungalows memiliki karyawan berjumlah hanya 15 orang dengan masing-masing orang memiliki divisi masing-masing. Tidak ada kebijakan khusus oleh usaha ini karna saat penurunan kunjungan terjadi para karyawan melakukan reparasi kecil seperti pengecatan ulang kayu perawatan bangunan dan merawat kebersihan bungalow. Sedangkan pada Old Man's tidak terjadi penurunan dan tidak ada kebijakan baru yang dikeluarkan oleh perusahaan. Hanya saja karyawan dihimbau untuk lebih perhatian pada wisatawan untuk mengingatkan keselamatan wisatawaan saat rupsi berlangsung.

\section{Pendapatan kondisi ekonomi pekerja}

Pendapatan kondisi ekonomi pekerja tidak terjadi perubahan karena kebijakan dari perusahaan memang tidak mengurangi gaji karyawan walaupun terjadi penurunan kunjungan wisatawan terjadi pasca erupsi.

\section{Alternatif pekerjaan lain}

Sehubungan tidak adanya perubahan gaji dan tidak ada kebijakan khusus, yang berlangsung sebelum erupsi, saat erupsi terjadi dan setelah erupsi terjadi pada setiap usaha pariwisata terlebih pada usaha pariwisata Bali Laksita home stay, The Calmtree Bungalows, The Lawn lounge beach dan Old Man's maka dapat disimpulkan bahwa pelaku usaha atau karyawan yang bekerja pada usaha pariwisata tersebut tidak memiliki alternatif pekerjaan lain. Alternatif pekerjaan lain ini untuk menggantikan atau cadangan pekerjaan lain saat usaha pariwisata tersebut tidak dapat menerima atau memberhentikan karyawan tersebut. Alternatif pekerjaan lain ini juga dapat meningkatkan pendapatan pekerja usaha pariwisata saat pekerjaan sebelumnya telah mengalami keterpurukan. Namun hal tersebut tidak terjadi pada karyawan yang bekerja pada Bali Laksita home stay, The Calmtree Bungalows, The Lawn lounge beach dan Old Man's. Hal ini disebab kan karena kondisi usaha pada usaha pariwisata tersebut tetap stabil dan berjalan normal seperti biasa walaupun ada sedikit penurunan, namun penurunannya tidak berkepanjangan atau sementara

\section{SIMPULAN DAN SARAN Simpulan}

- Lokasi penelitian berada di kawasan Pantai Batu Bolong. Infroman yang di gunakan untuk mengumpulkan data adalah manager atau yang mewakili pada usaha pariwisataBali Laksita home stay, The Calmtree Bungalows, dan Old Man's. serta pekerja yang bekerja pada usaha pariwisata tersebut. Kondisi usaha dominan mengatakan bahwamenurun tingkat kunjungannya tetapi tidak menurunkan omzet yang sangat ekstrim hanya pada kisaran di 
bawah 50\%, terkecuali Old Man's yang memang tidak pernah sepi pengunjung. Dari penurunan yang tidak terlalu ekstrim tidak ada kebijakan khusus yang dikeluarkan untuk pekerja sebagai manajemen krisis usaha pasca erupsi terjadi. Hal ini disebabkan kunjungan wisatawan ke Pantai Batu Bolong tidak pernah sepi peminatnya terutama wisatawan yang ingin melakukan aktivitas surfing. Jadi, dari tingginya kunjungan ke Pantai Batu Bolong untuk surfing tersebut dapat menolong kondisi ekonomi usaha pariwisata yang ada di kawasan Pantai Batu Bolong.

Kondisi sosial ekonomi pelaku usaha pariwisata yang bekerja pada usaha Bali Laksita home stay, The Calmtree Bungalows dan Old Man's, tidak mengalami nasib yang buruk seperti pemberhentian sementra, PHK, penurunan gaji, atau penggantian jam kerja. Hal ini disebabkan tidak adanya kebiakan khusus saat erupsi terjadi. Keijakan tersebut tidak muncul karena saat erupsi terjadi seluruh kegiatan di kawasan Pantai Batu Bolong tidak terganggu sama sekali. Banyaknya informan menyampaikan bahwa usaha pariwisata yang terpuruk kebanyakan ada di kawasan Kuta, Legian, Seminyak dan Ubud. Jadi pendapatan yang di terima karyawan tetap stabil, status nikah karyawan mayoritas masih singel jadi tidak perlu memikirkan kondisi ekonomi keluarga yang juga ditambah bahwa tidak ada penurunan gaji atau pendapatan.

\section{Saran}

Saran bagi pemilik usaha pariwisata di kawasan Pantai Batu Bolong agar memberikan kebijakan mengenai keamanan, baik bagi wisatawan maupun para pekerja. Seperti hal kecil dilakukan breafing mengenai erupsi Gunung Agung agar lebih wasapada namun tidak panik. Dan mengarahkan pekerja bagaimana menghadapi wisatawan yang menanyakan mengenai erupsi Gunung Agung. Hal tersebut bertujuan untuk memberikan rasa aman bagi wisatawan dan rasa nyaman saat berkunjung ke usaha pariwisata yang dimiliki bahkan juga akan menciptakan mind set yang tidak berlebihan bagi wisatawan mengenai erupsi Gunung Agung menimpa seluruh bagian Bali. Selanjutnya memberikan masker kepada pekerja dan wisatawan untuk antisipasi bila ada hujan debu di kawasan Pantai Batu Bolong, Canggu.

Saran untuk penelitian selanjutnya dapat dikaji mengenai dampak pasca erupsi Gunung Agung terhadap sosial ekonomi pelaku usaha sekala kecil di kawasan Pantai Batu Bolong, Canggu. Atau juga dapat mengkaji pada lokasi yang berbeda di daerah Bali bagian selatan seperti Seminyak, Kuta dan Legian sesuai dengan informasi yang diberikan oleh informan-informan dalam penelitian ini.

\section{DAFTAR PUSTAKA}

Bhaskara, Gde Indra."Gunung Berapi dan Pariwisata: Bermain Dengan Api".Jurnal Analisis Pariwisata 17.1: 31-40.

Bungin, Burhan.2003.Analisis Data Penelitian Kualitataif.Jakarta:Raja Grapindo Persada

Bungin, Burhan.2007.Metode Penelitian Kualitataif.Jakarta:Raja Grapindo

Fink Steven.1986.Crisis Mnagement:Planing for the Inevitable.Amerika:American Management Association.

Ilham, Nyak.2010.“Dampak Erupsi Gunung Merapi Terhadap Kondisi Sosial Ekonomi Petani."

Khasali, Rhenald.2003.Manajemen Public Relations Konsep dan Aplikasinya di Indonesia.Jakarta.Pustaka Utama Grafiti.

Koentjaraningrat 1993. Metode Penelitian Masyarakat. Jakarta:Gramedia.

Moleong , Lexy J..2000.Metode Penelitian Kualitatif.Bandung:Remaja Rosdakarya. Sugiyono.2008.Metode Penelitian Bisnis.Bandung:Alfabeta.

Pitana I Gde \& Putu G. Gayatri.2005.Sosiologi Pariwisata.Yogyakarta:Andi offset.

Saputri, Catur Dewi.Perubahan Sosial-Ekonomi Masyarakat Penambang Pasir Pasca Erupsi Merapi Tahun 2010 Di Dusun Kojor, Kelurahan Bojong, Kecamatan Mungkid, Kabupaten Magelang. Diss. Fakultas Ilmu Sosial, 2012.

Sugiyono.2003.Memahami Penelitian Kualitatif.CV :ALFABETA.Bandung.

Wibowo, Lili Adi.2018."Usaha Jasa Pariwisata" Makalah Disajikan pada Pendidikan dan Latihan Profesi Guru (PLPG) Bidang Keahlian Manajemen Bisnis, Bandung 15.

Windriati, Fika Suci.2011."Analisa.Manajemen Krisis PT. Pelabuhan Indonesia II (Persero) Cabang Pontianak Dalam Peristiwa Tenggelamnya Kapal Di Alur Pelayaran Pelabuhan.Diss.UPN"VETERAN" YOGYAKARTA.

Sumber Lain:

Profil Desa Canggu Tahun 2016-2017 
Undang-Undang Tentang Kepariwisataan No. 10 Tahun 2009 Bab I Pasal 1

Undang-Undang No. 9 Tahun 1990

Undang-Undang Tentang Ketenagakerjaan Nomor 13

Tahun 2003 